\title{
Postharvest UV-B treatments increased fructose content of tomato (Solanum lycopersicon L. cv. Tayfun F1) harvested at different ripening stages
}

\author{
Mehmet Ufuk KASIM ${ }^{1,2}$, Rezzan KASIM ${ }^{1,2 *}$
}

\begin{abstract}
In the postharvest stage, taste and flavor are the key components of the marketability of tomato. Therefore, greater emphasis is now being placed on improving traits such as sugar content. In this study postharvest ultraviolet-B (UV-B) treatments on sugar, total soluble solids, and color of tomatoes harvested at different stages were investigated. Tomatoes harvested at turning, pink, and red stages were treated with two different doses of UV-B irradiation: UVB4 and UVB8. Color $L^{*}$ and hue angle values of tomatoes treated with UV-B were found to be high, which means the red color of tomatoes was improved. UVB4 treatments increased the color $\mathrm{a}^{*}$ and saturation index values of tomatoes at pink and red harvest stage, although it did not affect at the turning stage. Additionally, UV-B irradiation treatments had no effect on sucrose content of the tomatoes. Fructose, glucose, and TSS content of tomatoes treated with UVB8 at red harvest stage were found to be high. Hence, the results obtained from this study are of great importance in terms of providing an increase in the amount of sugar without the need for breeding, and also consumer satisfaction.
\end{abstract}

Keywords: tomato; UV-B; color; glucose; fructose; sucrose.

Practical Application: Sugars, acids, phenols, and minerals, are the main constituents of tomato taste with sugars, quantitatively, making the largest contribution. Higher fructose, glucose, and TSS content of tomatoes result in increased sweetness and better tasting tomatoes, and ultimately consumer satisfaction.

\section{Introduction}

Tomato is one of the most important vegetable crops worldwide because of its high consumption, year around availability, and large content of healthy components. Tomato is an important supplier of nutrients such as folate, potassium, vitamins A and C, flavonoids, and carotenoids (Beecher, 1997).

Tomato shows great differences in fruit characteristics in terms of size, shape, and color, and is a climacteric fruit and continues to ripen even after harvesting. Depending on consumer and market requirements, tomatoes are harvested at different stages of ripening from breaking to red color (Wold et al., 2004). During ripening, the green pigment chlorophyll degrades and carotenoids are synthesized. These carotenoids largely influence the quality perception of fresh tomatoes. For fresh tomatoes, texture and color are the most important quality attributes, which directly relate to their marketing value (Tijskens \& Evelo, 1994).

Ultraviolet (UV) radiation is used to maintain the postharvest quality and extend the shelf life of several fresh fruits and vegetables. Although there is more research going on the effect of postharvest UV-B treatment on other crops such as, broccoli (Aiamla-or et al., 2010), grapes (Cantos et al., 2000), mushrooms (Roberts et al., 2008), and apples (Hagen et al., 2007), very limited study has been done in case of tomato in the past decades.

These studies focused on the effect of UV-B irradiation on the quality properties of tomatoes, especially, sensory quality and antioxidant property (Liu et al., 2011), and nutraceutical and physical properties (Castagna et al., 2013). Liu et al. (2011), stated that UV-B irradiation appears to be a useful nonchemical way of maintaining postharvest quality and enhancing antioxidant capacity of tomato fruit. So, this study aims to evaluate the effect of postharvest UV-B treatments on color, total soluble solids (TSS), and sugar content of tomatoes harvested at different maturation stages during storage.

\section{Materials and methods}

\subsection{Plant material}

Tomatoes (Solanum lycopersicum L. cv. Tayfun F1) used in this study were grown in the greenhouse at Arslanbey Vocational School, in Kocaeli University, during the production period of 2014. Seedlings of omato plants were sowed in March, and observed during the development stage, and also were harvested at five different maturation stages, defined in Table 1 (United States Departmente of Agricultre, 1991).

\section{2 $U V-B$ radiation treatments}

The UV-B radiation device consisted of two banks of three stainless-steel reflectors with unfiltered germicidal emitting lamps (TUV 30 W/T8 Philips, Holland) located $30 \mathrm{~cm}$ above the 
Table 1. Tomato ripening stage in accordance with USDA color standards (United States Departmente of Agricultre, 1991).

\begin{tabular}{cl}
$\begin{array}{c}\text { Surface } \\
\text { color }\end{array}$ & \multicolumn{1}{c}{ Definition } \\
\hline Green & $\begin{array}{l}\text { The surface of the tomato is completely green in color. } \\
\text { The shade of green color may vary from light to dark. }\end{array}$ \\
\hline Breaker & $\begin{array}{l}\text { Break in color from green to tannish-yellow, pink or red on } \\
\text { not more than 10 percent of the surface. }\end{array}$ \\
\hline Turning & $\begin{array}{l}\text { More than } 10 \text { percent but not more than } 30 \text { percent of the } \\
\text { surface, in the aggregate, shows a definite change in color } \\
\text { from green to tannish-yellow, pink, red. }\end{array}$ \\
\hline Pink & $\begin{array}{l}\text { More than } 30 \text { percent but not more than } 60 \text { percent of the } \\
\text { surface, in the aggregate, shows pink or red color. }\end{array}$ \\
\hline Red & $\begin{array}{l}\text { More than } 90 \text { percent of the surface, in the aggregate, } \\
\text { shows red color. }\end{array}$ \\
\hline
\end{tabular}

radiation vessel. Prior to use, the lamps were allowed to stabilize by turning them on at least $15 \mathrm{~min}$ before. The packaged tomatoes were placed on the upper surface at a distance of $30 \mathrm{~cm}$ from the screen. The product was irradiated in a cold room at $5{ }^{\circ} \mathrm{C}$ to avoid a temperature increase during the treatments. UV-B measurements were taken with a radiometer to determine the spectral irradiance of the bare lamp (Kasım \& Kasım, 2014). Treatments used were: C: Control, non-treated; UVB4; Tomato fruits at different harvest stages irradiated with ultraviolet-B (UV-B) irradiation for $4 \mathrm{~min}\left(0.564 \mathrm{~kJ} \mathrm{~m}^{-2}\right)$; UVB8: Tomato fruits at different harvest stages irradiated with ultraviolet-B (UV-B) irradiation for $8 \mathrm{~min}\left(1.128 \mathrm{~kJ} \mathrm{~m}^{-2}\right)$

\subsection{Packaging and storage conditions}

After irradiation treatments, for each replicate, three tomatoes were placed into polystyrene foam dishes and wrapped with polyethylene (PE) stretch film. The tomatoes from this experiment were stored at $9 \pm 1{ }^{\circ} \mathrm{C}$ temperature and $95 \%$ relative humidity for 28 days. During the storage period, changes in quality were determined at every 7 days interval. Twelve fruit from each treatment (four replicates and three tomatoes each replicate) were evaluated for color changes, TSS, and sugar changes.

\subsection{Color measurements}

Color measurements ( $\mathrm{L}^{*}, \mathrm{a}^{*}$, and $\mathrm{b}^{*}$ values) were performed using a chromometer CR-400 (Konica Minolta, Inc. Osaka, Japan) equipped with illuminant D65 and $8 \mathrm{~mm}$ aperture of the instrument for illumination and measurement. The instrument was calibrated with a white reference tile $\left(\mathrm{L}^{*}=97.52, \mathrm{a}^{*}=-5.06\right.$, $\left.\mathrm{b}^{\star}=3.57\right)$ prior to measurements. The $\mathrm{L}^{\star}(0=$ black, $100=$ white $)$, $\mathrm{a}^{*}(+$ red, - green $)$, and $\mathrm{b}^{*}$ (+ yellow, - blue) color coordinates were determined according to the CIELab coordinate color space system (Radzevičius et al., 2014) Saturation index (SI, Equation 1) was calculated using measured $\mathrm{a}^{\star}$ and $\mathrm{b}^{*}$ values given as follows (Sarıçoban and Yllmaz, 2010):

$$
\cdot S I=\sqrt{a^{* 2}+b^{* 2}}
$$

\subsection{Total soluble solids (TSS)}

TSS were determined for each sample fruit in four replications using an Atago DR-A1digital refractometer (Atago Co. Ld., Japan) at $20^{\circ} \mathrm{C}$ and expressed as percent value (\%) (Ilić et al., 2015)

\subsection{Sugar analysis}

To $3 \mathrm{~g}$ of the fresh-cut tomatoes, $15 \mathrm{~mL}$ of water was added. This mixture was filtered through Whatman No. 1 filter paper, and then $20 \mu \mathrm{L}$ of filtrate was injected into the HPLC system (Agilent, HP 1260, Hewlett Packard, CA/USA). The HPLC conditions were as follows: Column: Zorbax Carbohydrate Analysis, $4.6 \mathrm{~mm} \mathrm{ID} \times 150 \mathrm{~mm}(5 \mu \mathrm{L})$; Mobile phase: 75/25 acetonitrile/water; Flow rate: $1.4 \mathrm{~mL} / \mathrm{min}$; Temperature: $30^{\circ} \mathrm{C}$, Detector B HP110 RID: $30^{\circ} \mathrm{C}$, Sample volume: $20 \mu \mathrm{L}$ in 50/50 acetonitrile/water (Kasım et al., 2015)

\subsection{Total Sweetness Index (TSI)}

TSI is used to indicate sweetness and is calculated as: TSI $=[(1.00 \times$ sucrose $)+(0.76 \times$ glucose $)+(1.50 \times$ fructose $)]$ (Clarke, 1995).

\subsection{Statistical analysis}

Experiments were conducted in a completely randomized design with a minimum of three replications per storage treatment per sampling date. Data were analyzed by ANOVA and differences among means were determined by the Duncan's multiple range test with significance level at $\mathrm{p}<0.05$.

\section{Results and discussions}

\section{$3.1 L^{\star}$ and Hue angle values}

$\mathrm{L}^{*}$ values of tomato fruits at different maturity stages are shown in Figure 1 and the changes in the $\mathrm{L}^{*}$ color values of tomatoes during storage period are given in Table $2 . \mathrm{L}^{*}$ value of green tomatoes was found to be 65.934 , which decreased during maturation and ripening period (59.938, 54.756, 47.914, and 40.488 for breaker, turning, pink, and red harvest stages, respectively). Moreover, differences among the maturation stages were found statistically significant at $p \leq 0.05$. Similarly, $L^{*}$ color values of tomatoes harvested at different maturation stages were decreased during storage period in all treatment groups. But, $\mathrm{L}^{*}$ values of tomatoes at all harvest stages were high in control group compared with UVB4 or UVB8 treatments at the 7th and 21 st day of storage . However, $L^{*}$ values of tomatoes at red stage were higher compared with other treatments on the 14th day, and also differences among the treatments were significant (Table 2). Additionally, hue angle values of tomatoes, showing similar trends, were also confirmed with this result (Figure 1, Table 2). In the present study, color $\mathrm{L}^{*}$ values of tomatoes in control group at all harvest stages were found to be high; whereas it was low in UVB4 and UVB8 treatments. Hence, this result showed that UV-B irradiation accelerated the color development in tomatoes. Furthermore, these results were also in agreement with the hue angle values of tomatoes, which gives real color results in fruits and vegetables. In a previous study, Liu et al. (2011), reported that in mature-green (breaker) tomato fruit 20 or $40 \mathrm{~kJ} / \mathrm{m}^{2} \mathrm{UV}$-B irradiation was most effective in maintaining a high level of firmness and delaying the color development. But, in this study, UV-B treatments at different harvest stages accelerated the color development during storage period. For fresh tomatoes, texture and color are the most important 

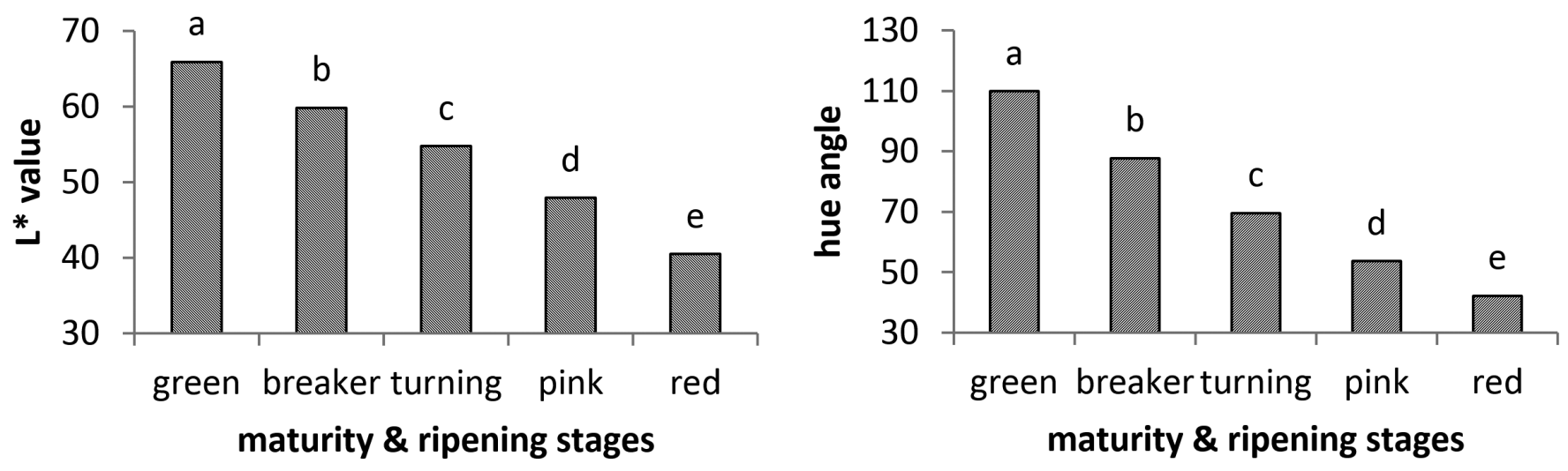

Figure 1. Color $L^{\star}$ and hue angle values of tomatoes at different harvest maturity. Each bar is the mean twelve fruits. Means with different letters are significantly different at the $\mathrm{p} \leq 0.05$.

Table 2. Color L and Hue angle values of tomatoes treated with different ultraviolet-B (UV-B) irradiation at different harvest stages during postharvest storage period.

\begin{tabular}{|c|c|c|c|c|c|c|c|}
\hline & & \multicolumn{3}{|c|}{$\mathrm{L}$ value } & \multicolumn{3}{|c|}{ Hue angle } \\
\hline & & $7^{\text {th }}$ day & $14^{\text {th }}$ day & $21^{\text {th }}$ day & $7^{\text {th }}$ day & $14^{\text {th }}$ day & $21^{\text {th }}$ day \\
\hline \multirow{3}{*}{ Turning } & Control & 52.6 & 46.7 & 43.7 & 66.9 & 53.2 & 48.8 \\
\hline & UVB4 & 49.0 & 45.2 & 42.6 & 59.4 & 50.3 & 47.7 \\
\hline & UVB8 & 51.1 & 48.3 & 43.5 & 64.8 & 58.5 & 47.3 \\
\hline \multirow[b]{2}{*}{ Pink } & Control & 47.4 & 42.4 & 42.3 & 57.0 & 48.3 & 47.4 \\
\hline & UVB4 & 47.5 & 42.5 & 40.6 & 60.4 & 49.1 & 45.7 \\
\hline \multirow[t]{2}{*}{ Red } & UVB4 & 43.2 & 39.3 & 39.5 & 50.5 & 45.7 & 45.0 \\
\hline & UVB8 & 43.0 & 42.0 & 38.9 & 49.4 & 47.8 & 44.4 \\
\hline \multicolumn{2}{|c|}{ Maturity \& rip. stag. } & $* * *$ & ${ }^{* * *}$ & $* * *$ & $* * *$ & $* * *$ & $* * *$ \\
\hline \multicolumn{2}{|c|}{ Treatment } & ns & * & ns & ns & ${ }^{* *}$ & ns \\
\hline \multicolumn{2}{|c|}{ Maturity $x$ treatment } & ns & ns & ns & ns & ns & ns \\
\hline
\end{tabular}

quality attributes, which directly relate to their marketing value (Tijskens \& Evelo, 1994). Therefore, the improvement of color by UV-B irradiation is an important outcome of this study for the quality of tomato.

\subsection{Color $a^{\star}$ and saturation index values}

$a^{*}$ color values and saturation index of tomatoes were increased during maturation/ripening period (Figure 2), and differences among maturation stages were statistically significant at $\mathrm{p} \leq 0.05$ level. During maturation/ripening, the green pigment chlorophyll degrades and carotenoids are synthesized. Carotenoids, particularly lycopene and $\beta$-carotene, represent the primary components of ripe fruit pigmentation in tomato pericarp and are responsible for the characteristic color of ripe tomatoes, conferring deep red and orange colors, respectively. These carotenoids largely influence the quality perception of fresh tomatoes (Tijskens \& Evelo, 1994). Although a value of tomatoes at the harvest period was low, it increased during storage for all three maturation periods. In turning stage, $\mathrm{a}^{\star}$ color value of tomatoes was lower in UVB8 treatment compared with control and UVB4 treatments, until the 14th day of the storage, and also differences among treatments were statistically significant (Table 3). In the pink and red stage, however, the UVB4 treatment was more effective compared with UVB8 treatment for the color development of tomatoes. Saturation index values of tomatoes were increased during maturation/ripening stage, and the differences among the harvesting stages were significant at $\mathrm{p} \leq 0.05$. After harvest, according to saturation index values (Table 3), both UVB4 and UVB8 treatments delayed the color development until the 14th day of storage at turning and pink stage. But, color development of tomatoes harvested at red stage accelerated with ultraviolet irradiation treatments compared with control group. At the end of the storage, the saturation index values of tomatoes were found to be high in control group for both pink and red stage (48.0 and 46.6, respectively) compared with tomatoes at the turning stage. Therefore, it can be said that color development of tomatoes at pink and red harvest stage was delayed by UV-B irradiation. Liu et al. (2011) found that, in tomatoes, the optimum dose of UV-B for maintaining sensory quality and enhancing antioxidant capacity was 20 or $40 \mathrm{~kJ} \mathrm{~m}^{-2}$.

According to researchers with the highest dose of $80 \mathrm{~kJ} \mathrm{~m}^{-2} \mathrm{UV}-\mathrm{B}$ treatment showed negative effect on color. In the present study, use of UVB4 and UVB8 treatments did not show any negative effect 
Table 3. Color $\mathrm{a}^{*}$ and saturation index values of tomatoes treated with different ultraviolet-B (UV-B) irradiation at different harvest stages during postharvest storage periods.

\begin{tabular}{|c|c|c|c|c|c|c|c|}
\hline & & \multicolumn{3}{|c|}{$\mathrm{a}^{\star}$ value } & \multicolumn{3}{|c|}{ Saturation index } \\
\hline & & $7^{\text {th }}$ day & $14^{\text {th }}$ day & $21^{\text {th }}$ day & $7^{\text {th }}$ day & $14^{\text {th }}$ day & $21^{\text {th }}$ day \\
\hline \multirow{3}{*}{ Turning } & Control & 14.9 & 27.7 & 29.3 & 38.2 & 46.2 & 44.5 \\
\hline & UVB4 & 21.5 & 28.1 & 30.0 & 42.3 & 44.0 & 44.5 \\
\hline & UVB8 & 16.4 & 23.2 & 30.5 & 38.2 & 44.5 & 45.0 \\
\hline \multirow{3}{*}{ Pink } & Control & 23.7 & 31.2 & 32.4 & 43.4 & 46.8 & 48.0 \\
\hline & UVB4 & 20.5 & 29.1 & 31.0 & 41.2 & 44.5 & 44.4 \\
\hline & UVB8 & 24.8 & 27.0 & 32.0 & 45.5 & 46.4 & 47.1 \\
\hline \multirow{3}{*}{ Red } & Control & 27.1 & 31.7 & 33.7 & 48.2 & 46.2 & 46.6 \\
\hline & UVB4 & 30.8 & 32.5 & 31.3 & 48.4 & 46.6 & 44.2 \\
\hline & UVB8 & 30.8 & 32.7 & 31.6 & 47.3 & 48.7 & 44.3 \\
\hline \multicolumn{2}{|c|}{ Maturity \& rip. stag. } & $* *$ & ${ }^{* *}$ & ${ }^{*}$ & ${ }^{* *}$ & ${ }^{*}$ & ns \\
\hline \multicolumn{2}{|c|}{ Treatment } & ns & * & ns & ns & ns & ns \\
\hline \multicolumn{2}{|c|}{ Maturity $x$ treatment } & ns & ns & ns & ns & ns & ns \\
\hline
\end{tabular}

${ }^{*}$ Significant at $\mathrm{p}<0.05 .{ }^{*}$ Significant at $\mathrm{p}<0.001$. ns: non-significant. Numbers given in the table is the average of four replications and twelve fruits.
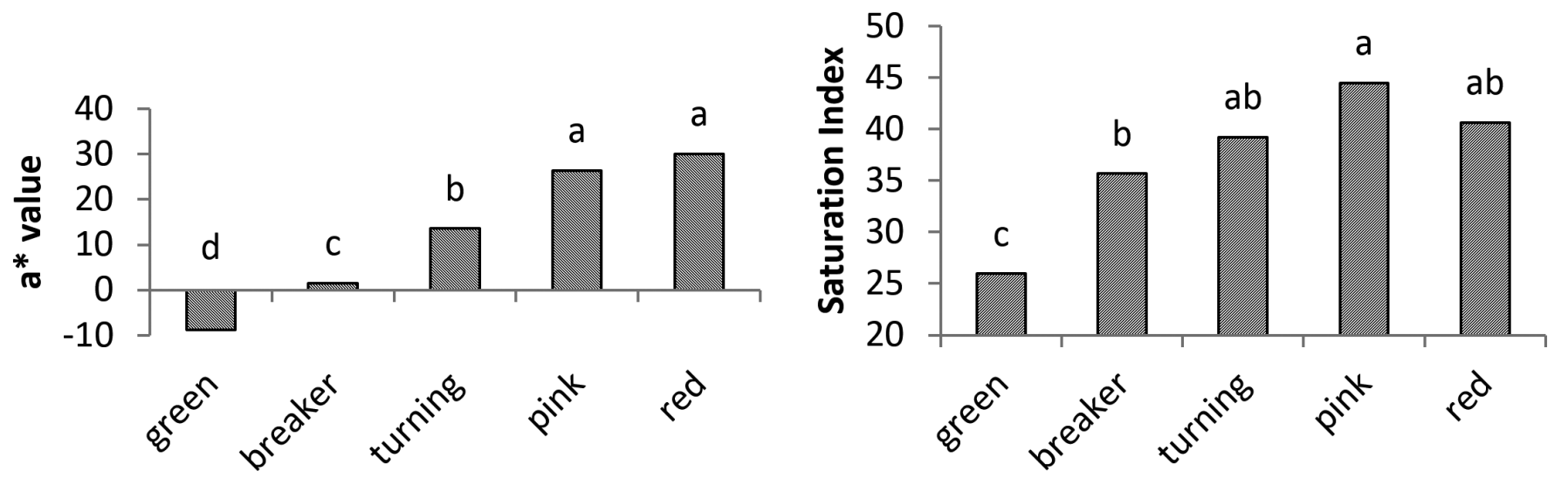

maturity \& ripening stages

Figure 2. Color $\mathrm{a}^{*}$ and saturation index values of tomatoes at different harvest maturity. Each bar is the mean twelve fruits. Means with different letters are significantly different at $\mathrm{p} \leq 0.05$.

on color of tomatoes in any of the harvest stages. Conversely, it was found that the red color formation of tomatoes accelerated with the use of ultraviolet irradiation until the $21^{\text {st }}$ day of storage, except for tomatoes at the turning stage. Also this phenomenon showed the positive effect of ultraviolet irradiation on color development of tomatoes. This results may be due to UV-B doses of applied in this research is lower than the researchers. Maneerat et al. (2003) reported that UV-A irradiated tomatoes show normal color development and fruit ripening without any physiological disorder. Similarly, Maharaj et al. (1999) reported that UV-C irradiation at $3.7 \mathrm{~kJ} \mathrm{~m}^{-2}$ and $24.4 \mathrm{~kJ} \mathrm{~m}^{-2}$ delays the development of tomato tissue color and softening. Hence, the results of the present study were compatible with the previous studies with the UV-B treatment conditions.

\subsection{Total soluble solids (TSS)}

The total soluble solids (TSS) content of tomatoes was increased during the development, maturation, and ripening stage (Figure 3). Before the harvest, TSS content of tomatoes was

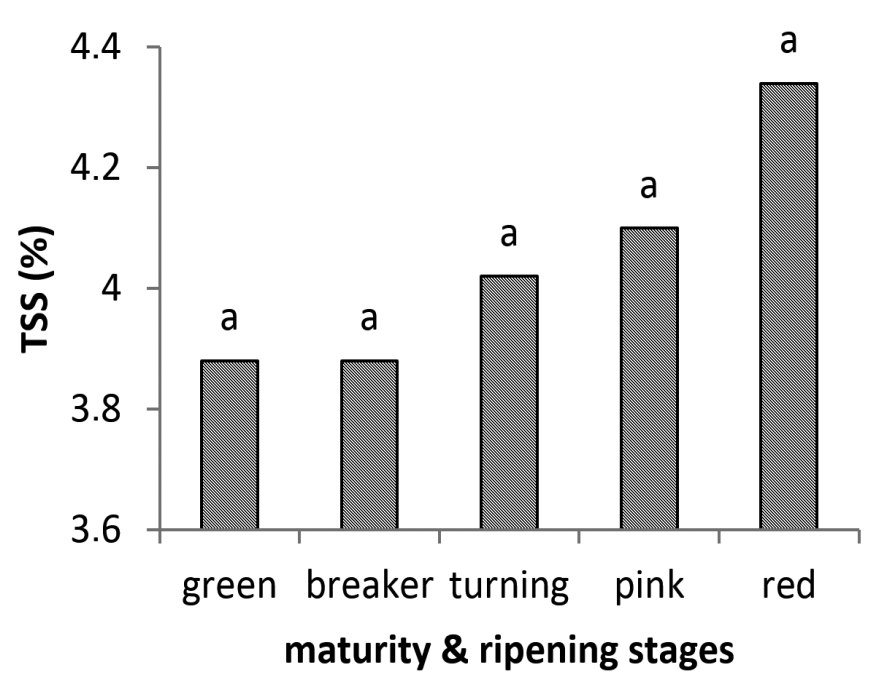

Figure 3. Total soluble solids (TSS) of tomatoes at different harvest maturity. Each bar is the mean twelve fruits. Means with different letters are significantly different at the $\mathrm{p} \leq 0.05$. 
$3.88,3.88,4.02,4.1$, and $4.3 \%$ for green, breaker, turning, pink, and red harvest stages, respectively. Previous studies reported that TSS for large beefsteak tomatoes ranged from 3 to $5 \%$, for medium-sized fruit from 5 to $7 \%$, and for cherry tomatoes from 9 to $15 \%$ (Gautier et al., 2010; Luengwilai et al., 2010a). In this study, TSS content of tomatoes was changed between 3.88 and 4.3 so that it can be said that TSS content of tomato studied in the present study is similar to that of beefsteak tomato. The TSS content of tomatoes at all harvest stages and in all treatment groups did not show any significant change during the postharvest storage (Table 4). However, the TSS content of tomatoes treated with UVB8 at the red stage was higher compared with other treatments, at the 14th day of storage. The TSS is a refractometric index that indicates the proportion (\%) of dissolved solids in a solution. It is the sum of sugars (sucrose and hexoses; 65\%), acids (citrate and malate; 13\%), and other minor components (phenols, amino acids, soluble pectins, ascorbic acid, and minerals) in the tomato fruit pulp (Balibrea et al., 2006). So in the present study, both fructose and glucose content of tomatoes treated with UVB8 at red harvest stage were found to be high, along with the TSS content of the same period. Therefore, it was declared that both
TSS and soluble sugars of tomatoes were increased by high doses of UV-B irradiation.

\subsection{Sucrose, fructose and glucose content}

Sucrose content of tomatoes at green mature stage was high and decelerated during maturation (Figure 4) before harvest, and differences among harvest stages were not statistically significant at $\mathrm{p} \leq 0.05$. The sucrose content of tomatoes at harvest was $0.024,0.021$, and 0.003 for turning, pink, and red harvest stages, respectively. But after harvest, little or no sucrose content was found in tomatoes at all treatments and harvest stages. In previous studies, sucrose content of tomato was $0.09 \%$ for moneymaker cultivar (at 63 DPA, Luengwilai et al., 2010b), 0\% for Alisa craig cultivar at red harvest stage (Vogel et al., 2010), and $0 \%$ for Clothide cultivar at breaker stage (Vermeir et al., 2009). In the present study, the sucrose content of tomatoes at turning stage was $0.13,0$, and 0.06 in C, UVB4, and UVB8 treatments respectively. Furthermore, on the $7^{\text {th }}$ day, when the tomatoes were at the pink stage, sucrose was encountered only in the control group; however, there was sucrose only in red ripe tomatoes treated with UVB8 irradiation (Table 5). Also, there were only on the $7^{\text {th }}$ day

Table 4. Total soluble solids (TSS) of tomatoes treated with different ultraviolet-B (UV-B) irradiation at different harvest stages during postharvest storage period.

\begin{tabular}{|c|c|c|c|c|}
\hline & & \multicolumn{3}{|c|}{ TSS } \\
\hline & & $7^{\text {th }}$ day & $14^{\text {th }}$ day & $21^{\text {th }}$ day \\
\hline \multirow[b]{2}{*}{ Turning } & Control & 3.9 & 4.0 & 3.8 \\
\hline & UVB4 & 4.1 & 4.0 & 3.5 \\
\hline \multirow{3}{*}{ Pink } & Control & 3.9 & 4.0 & 4.2 \\
\hline & UVB4 & 4.0 & 3.9 & 4.2 \\
\hline & UVB8 & 4.0 & 3.9 & 3.7 \\
\hline \multirow[t]{2}{*}{ Red } & UVB4 & 4.0 & 3.8 & 4.0 \\
\hline & UVB8 & 4.2 & 4.4 & 4.0 \\
\hline \multicolumn{2}{|c|}{ Maturity \& rip. stag. } & ns & ns & ${ }^{*}$ \\
\hline \multicolumn{2}{|c|}{ Treatment } & ns & ns & ns \\
\hline \multicolumn{2}{|c|}{ Maturity $x$ treatment } & ns & ns & ns \\
\hline
\end{tabular}

${ }^{\star}$ Significant at $\mathrm{p}<0.01$. ns: non-significant. Numbers given in the table are the average of four replications and twelve fruits.

Table 5. Fructose, glucose and sucrose values of tomatoes treated with different ultraviolet-B (UV-B) irradiation at different harvest stages during postharvest storage period.

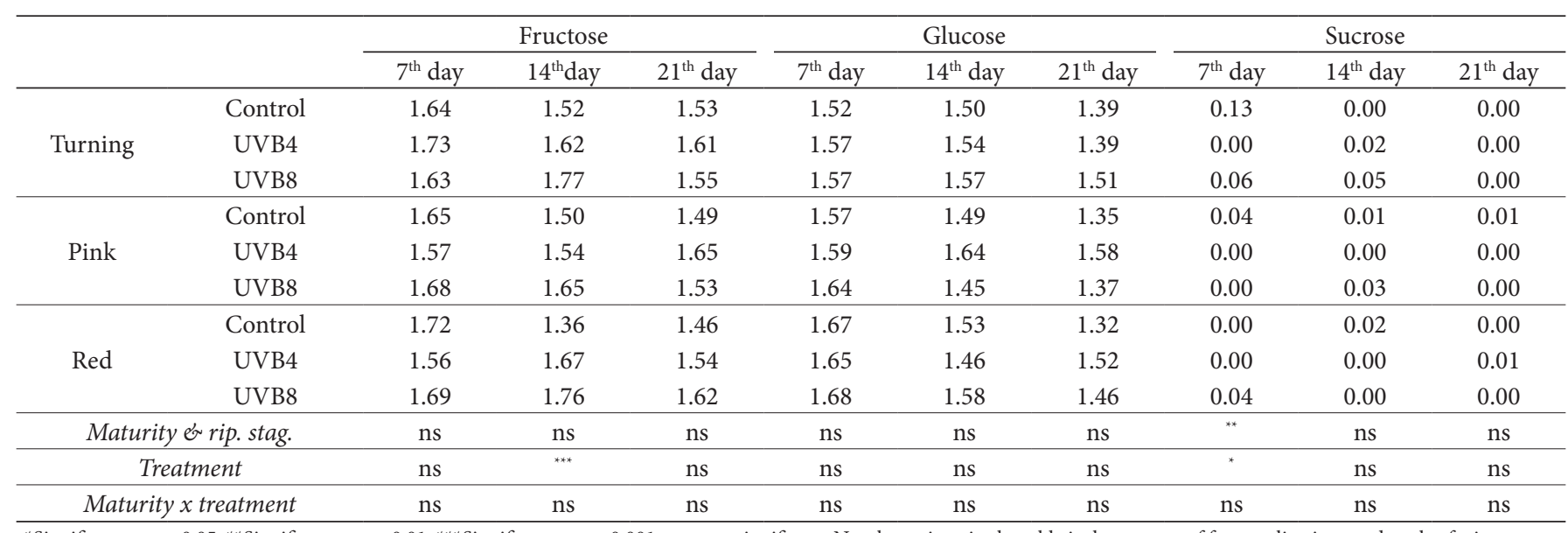

${ }^{*}$ Significant at $\mathrm{p}<0.05 .{ }^{*}$ Significant at $\mathrm{p}<0.01 .{ }^{* *}$ Significant at $\mathrm{p}<0.001$. ns: non-significant. Numbers given in the table is the average of four replications and twelve fruits. 
important changes observed with regard to sucrose content of tomatoes during storage period. Consequently, the data obtained with this research were in accordance to previous studies. Also it was found that the ultraviolet-B irradiation did not affect sucrose content of tomatoes at all harvest stages.

Glucose and fructose content of tomatoes showed similar changes before harvest (Figure 4). The glucose and fructose content of tomatoes at green stage were 1.46 and 1.51 , respectively, and increased at breaker stage, but after that decreased until red harvest stage. The glucose and fructose content of tomato was 1.7 and $1.2 \%$ for moneymaker cultivar (at 63 DPA, Luengwilai et al., 2010b), 1.97 and $2.35 \%$ for Alisa craig cultivar at red harvest stage (Vogel et al., 2010), and 1.33 and $1.33 \%$ for Clothide cultivar at breaker stage (Vermeir et al., 2009). Therefore, glucose and fructose content of different cultivars were different from one another according to variety and maturation stage. Meanwhile, the glucose level of tomatoes was always lower than fructose level during maturation/ripening stages.

The fructose content of tomatoes at harvest was 1.62, 1.49, and 1.62 for turning, pink, and red harvest stages respectively, and increased in all treatments and at all harvest stages on day 7. The fructose content of tomatoes in control group at all harvest stages were decreased, and similar changes were obtained for tomatoes under UVB4 treatment at turning and pink stage on 14th day of storage. But the fructose content of tomatoes in UVB8 treatment at all harvest stages was higher than both control and UVB4 treatments, and differences between UVB8 treatment and the other treatments were significant (Table 5).
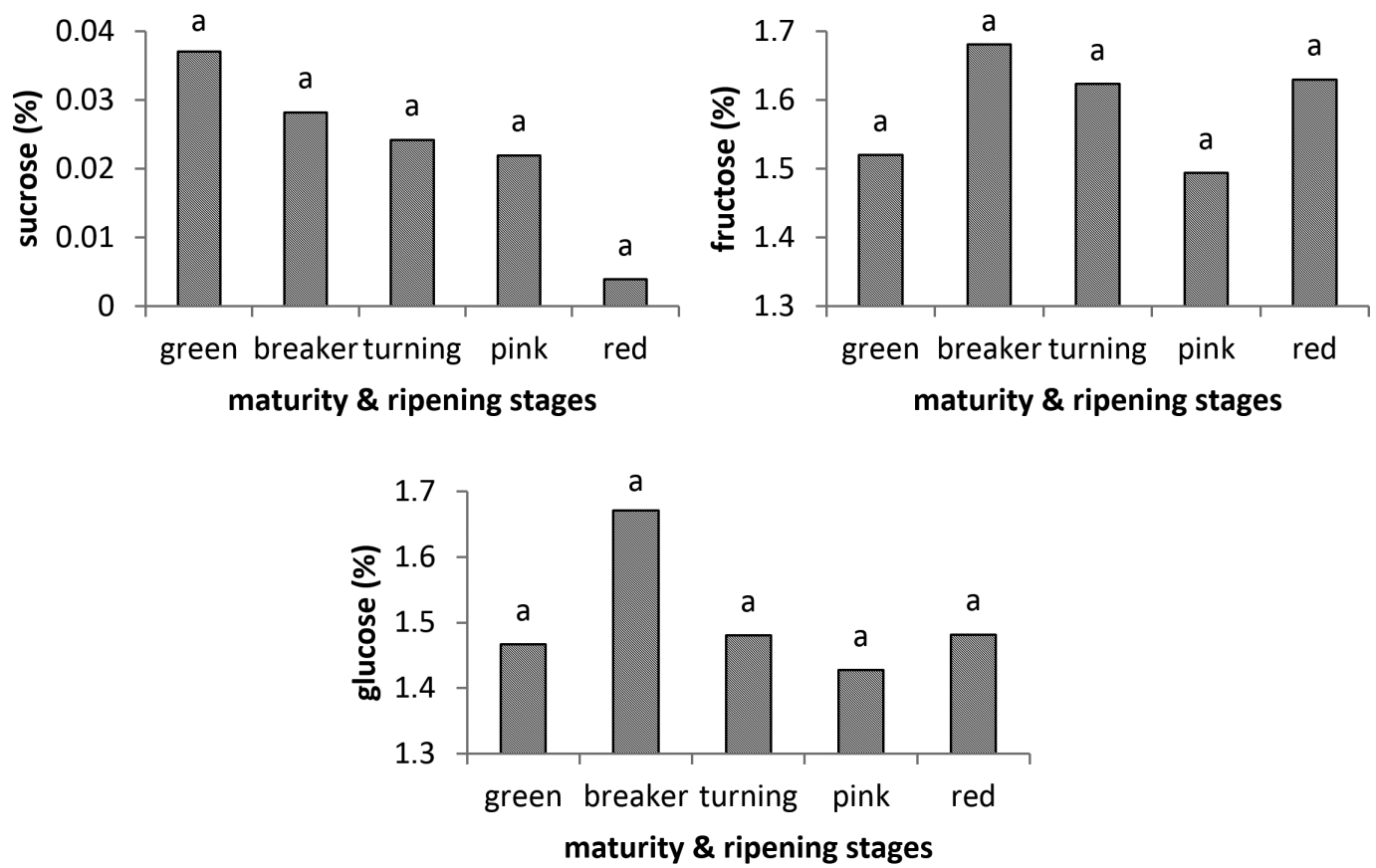

Figure 4. Fructose, glucose and sucrose values of tomatoes at different harvest maturity. Each bar is the mean twelve fruits. Means with different letters are significantly different at the $\mathrm{p} \leq 0.05$.

Table 6. Total sweetness index (TSI) of tomatoes treated with different ultraviolet-B (UV-B) irradiation at different harvest stages during postharvest storage period.

\begin{tabular}{|c|c|c|c|c|}
\hline & & \multicolumn{3}{|c|}{ TSI } \\
\hline & & $7^{\text {th }}$ day & $14^{\text {th }}$ day & $21^{\text {th }}$ day \\
\hline \multirow{3}{*}{ Turning } & Control & 3.75 & 3.42 & 3.34 \\
\hline & UVB4 & 3.79 & 3.62 & 3.47 \\
\hline & UVB8 & 3.70 & 3.89 & 3.49 \\
\hline \multirow{3}{*}{ Pink } & Control & 3.72 & 3.39 & 3.26 \\
\hline & UVB4 & 3.56 & 3.56 & 3.68 \\
\hline & UVB8 & 3.76 & 3.60 & 3.34 \\
\hline \multirow{3}{*}{ Red } & Control & 3.85 & 3.23 & 3.22 \\
\hline & UVB4 & 3.59 & 3.61 & 3.46 \\
\hline & UVB8 & 3.85 & 3.84 & 3.55 \\
\hline \multicolumn{2}{|c|}{ Maturity \& rip. stag. } & ns & ns & ns \\
\hline \multicolumn{2}{|c|}{ Treatment } & ns & $*$ & ns \\
\hline \multicolumn{2}{|c|}{ Maturity $x$ treatment } & ns & ns & ns \\
\hline
\end{tabular}

${ }^{\star}$ Significant at $\mathrm{p}<0.01 . \mathrm{ns}$ : non-significant. Numbers given in the table are the average of four replications and twelve fruits. 


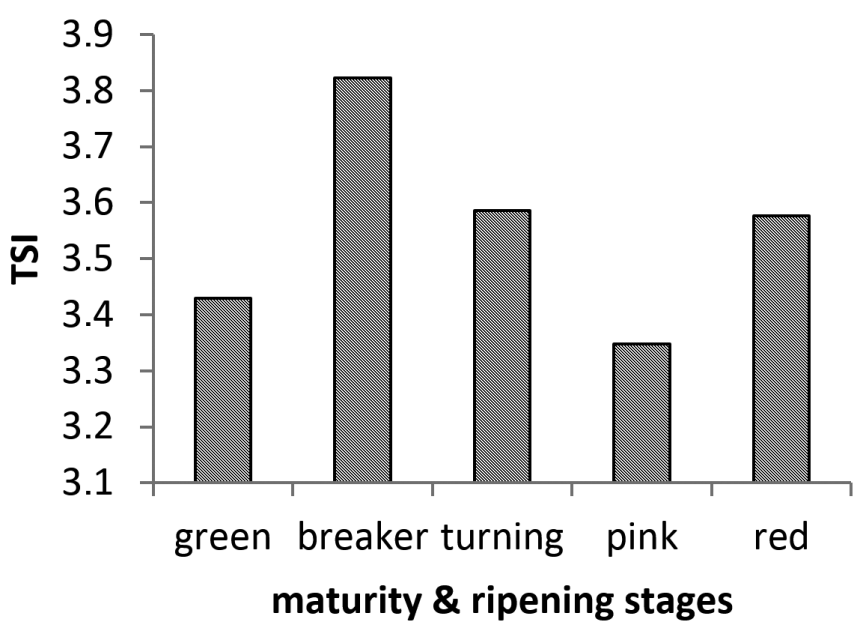

Figure 5. Total sweetness index (TSI) of tomatoes at different harvest maturity. Each bar is the mean twelve fruits.

At this time, fructose level of tomatoes in UVB8 treatments was $1.77,1.65$, and 1.76 for turning, pink, and red harvest stages, and followed by UVB4 and control group. Therefore, it suggests that UV-B irradiation at high levels increased the fructose content of tomatoes. In general, the glucose content of tomatoes in all treatment and at all harvest stages was lower than fructose level. The UV-B treatments did not show any important effect on glucose levels of tomatoes at any harvest stages; whereas, UVB8 treatment showed high glucose levels in tomatoes at the turning harvest stage, compared with control groups. However, glucose levels at pink and red harvest stages were high in UVB4 treatments. Flavor results from the complex interaction of taste and aroma. Sugars, acids, phenols, and minerals are the main constituents of tomato taste with sugars, quantitatively, making the largest contribution (Kader, 2008). Therefore increasing the sugar content of tomatoes increased the flavor and ultimately customer preference for tomatoes. In the present study fructose content of tomatoes was increased by both UVB4 and UVB8 treatments at all harvest stages, especially at the 14th day of storage. Also, fructose content of tomatoes in all harvest stages was higher than control group at the end of the storage period. These results are important for consumer satisfaction.

\subsection{Total sweetness index (TSI)}

The total sweetness index (TSI) was similar with that of the glucose and fructose content of tomatoes during maturation/ripening period (Figure 5). At the breaker stage, since both glucose and fructose content of tomato was high, TSI of the same period was also high. Then it decreased till red harvest stage. TSI of tomatoes was 3.58, 3.34, and 3.57 for turning, pink, and red harvest stages at harvest, and increased during postharvest storage period. The TSI of tomatoes treated with UVB4 and UVB8 at all harvest stages was higher than in control group on the 14th and 21st day of storage, and also differences among the treatments were statistically significant (Table 6).

Sugars and their influence on taste are gauged in several ways. TSS, the TSS-to-titratable acid ratio, and the TSI are three common measures. TSI is used to indicate sweetness. Fruit with identical total sugar content but with relatively more fructose or sucrose will taste sweeter (Beckles, 2012). Modern tomato cultivars store little sucrose and accumulate glucose and fructose in an approximate ratio of 1:1, therefore increasing fructose level is an important breeding target (Schaffer et al., 1999). The increase in fructose content by UV-B irradiation increased the TSI of tomatoes. Hence, these results are important in terms of providing an increase in the amount of sugar without the need for breeding.

\section{Conclusions}

In this study, TSS, sucrose, glucose, fructose content, and color properties of tomatoes harvested at different maturation stages were determined during the preharvest development stage. Furthermore, the postharvest ultraviolet treatment was given to tomatoes harvested at three different stages. So, both pre- and postharvest quality properties and the effect of UV-B irradiation treatments on tomatoes were studied. UV-B irradiation accelerated the red coloration of tomatoes at all harvest stages. In addition, glucose, fructose, and TSS content of tomatoes treated with UVB8 at red harvest stage was also found to increase. These results confirmed the TSI values.

\section{References}

Aiamla-or, S., Kaewsuksaeng, S., Shigyo, M., \& Yamauchi, N. (2010). Impact of UV-B irradiation on chlorophyll degradation and chlorophyll-degradingenzymeactivities in stored broccoli (Brassica oleracea L. Italica Group) florets. Food Chemistry, 120(3), 645-651. http://dx.doi.org/10.1016/j.foodchem.2009.10.056.

Balibrea, M. E., Martinez-Andujar, C., Cuartero, J., Bolarin, M. C., \& Perez-Alfocea, F. (2006). The high fruit soluble sugar content in wild Lycopersicon species and their hybrids with cultivars depends on sucrose import during ripening rather than on sucrose metabolism. Functional Plant Biology, 33(3), 279-288. http://dx.doi.org/10.1071/ FP05134.

Beckles, D. M. (2012). Factors affecting the postharvest soluble solids and sugar content of tomato (Solanum lycopersicum L.) fruit. Postharvest Biology and Technology, 63(1), 129-140. http://dx.doi. org/10.1016/j.postharvbio.2011.05.016.

Beecher, G. R. (1997). Nutrient content of tomatoes and tomato products. Proceedings of the Society for Experimental Biology and Medicine, 218(2), 98-100. http://dx.doi.org/10.3181/00379727-218-44282a. PMid:9605204.

Cantos, E., García-Viguera, C., Pascual-Teresa, S., \& Tomás-Barberán, F. A. (2000). Effect of postharvest ultraviolet irradiation on resveratrol and other phenolics of $\mathrm{Cv}$. Napoleon table grapes. Journal of Agricultural and Food Chemistry, 48(10), 4606-4612. http://dx.doi. org/10.1021/jf0002948. PMid:11052707.

Castagna, A., Chiavaro, E., Dall'Asta, C., Rinaldi, M., Galaverna, G., \& Ranieri, A. (2013). Effect of postharvest UV-B irradiation on nutraceutical quality and physical properties of tomato fruits. Food Chemistry, 137(1-4), 151-158. PMid:23200003.

Clarke, M. (1995). Carbohydrates, industrial. New York: Wiley-VCH.

Gautier, H., Lopez-Lauri, F., Massot, C., Murshed, R., Marty, I., Grasselly, D., Keller, C., Sallanon, H., \& Genard, M. (2010). Impact of ripening and salinity on tomato fruit ascorbate content and enzymatic activities related to ascorbate recycling. Functional Plant Science Biotechnology, 4, 66-75. 
Hagen, S. F. A., Borge, G. I. B., Bengtsson, G., Bilger, W., Berge, A., Haffner, K., \& Solhaug, K. A. (2007). Phenolic contents and other health and sensory related properties of apple fruit (Malus domestica Borkh., cv. Aroma): effect of postharvest UV-B irradiation. Postharvest Biology and Technology, 45(1), 1-10. http://dx.doi.org/10.1016/j. postharvbio.2007.02.002.

Ilić, Z. S., Milenković, L., Šunić, L., \& Fallik, E. (2015). Effect of coloured shade-nets on plant leaf parameters and tomato fruit quality. Journal of the Science of Food and Agriculture, 95(13), 2660-2667. http:// dx.doi.org/10.1002/jsfa.7000. PMID: 25389124.

Kader, A. A. (2008). Flavor quality of fruits and vegetables. Journal of the Science of Food and Agriculture, 88(11), 1863-1868. http:// dx.doi.org/10.1002/jsfa.3293.

Kasım, R., \& Kasım, M. U. (2014). Biochemical and color changes of fresh-cut melon (Cucumis melo L. cv. Galia) treated with UV-C. Food Science and Technology (Campinas.), 34(3), 547-551. http:// dx.doi.org/10.1590/1678-457x.6398.

Kasım, R., Kasım, M. U., \& Özer Uyar, G. E. (2015). Postharvest ascorbic acid treatments on color and sugar changes on fresh-cut carrot. International Journal of Research in Agriculture and Food Sciences, 2(10), 1-8.

Liu, C., Han, X., Cai, L., Lu, X., Ying, T., \& Jiang, Z. (2011). Postharvest UV-B irradiation maintains sensory qualities and enhances antioxidant capacity in tomato fruit during storage. Postharvest Biology and Technology, 59(3), 232-237. http://dx.doi.org/10.1016/j. postharvbio.2010.09.003.

Luengwilai, K., Tananuwong, K., Shoemaker, C. F., \& Beckles, D. M. (2010a). Starch molecular structure shows little association with fruit physiology and starch metabolism in tomato. Journal of Agricultural and Food Chemistry, 58(2), 1275-1282. http://dx.doi.org/10.1021/ jf9032393. PMid:20038101.

Luengwilai, K., Fiehn, O. E., \& Beckles, D. M. (2010b). Comparison of leaf and fruit metabolism in two tomato (Solanum lycopersicum L.) genotypes varying in total soluble solids. Journal of Agricultural and Food Chemistry, 58(22), 11790-11800. http://dx.doi.org/10.1021/ jf102562n. PMid:21033662.

Maharaj, R., Arul, J., \& Nadeau, P. (1999). Effect of photochemical treatment in the preservation of fresh tomato (Lycopersicon esculetum cv Capello) by delaying senescence. Postharvest Biology and Technology, 15(1), 13-23. http://dx.doi.org/10.1016/S09255214(98)00064-7.
Maneerat, C., Hayata, Y., Muto, N., \& Kuroyanagi, M. (2003). Investigation of UV-A light irradiation on tomato fruit injury. Journal of Food Protection, 66(11), 2168-2170. PMid:14627302.

Radzevičius, A., Viškelis, P., Viškelis, J., Karklelienė, R., \& Juškevičienè, D. (2014). Tomato fruit color changes during ripening on vine. International Journal of Biological, Biomolecular, Agricultural, Food and Biotechnological Engineering, 8(2), 112-114.

Roberts, J. S., Teichert, A., \& McHugh, T. H. (2008). Vitamin D2 formation from postharvest UV-B treatment of mushrooms (Agaricus bisporus) and retention during storage. Journal of Agricultural and Food Chemistry, 56(12), 4541-4544. http://dx.doi.org/10.1021/ jf0732511. PMid:18522400.

Sarıçoban, C., \& Yllmaz, M. T. (2010). Modelling the effects of processing factors on the changes in colour parameters of cooked meatballs using resporse surface methodology. World Applied Sciences Journal, 9(1), 14-22.

Schaffer, A. A., Petreikov, M., Miron, D., Fogelman, M., Spiegelman, M., Bnei-Moshe, Z., Shen, S., Granot, D., Hadas, R., Dai, N., Levin, I., Bar, M., Friedman, M., Pilowsky, M., Gilboa, N., \& Chen, L. (1999). Modification of carbohydrate content in developing tomato fruit. HortScience, 34, 1024-1027.

Tijskens, L. M., \& Evelo, R. W. (1994). Modelling colour of tomatoes during postharvest storage. Postharvest Biology and Technology, 4(1-2), 85-89. http://dx.doi.org/10.1016/0925-5214(94)90010-8.

United States Departmente of Agricultre - USDA. (1991). United States Standards for grades of fresh tomatoes. Washington: USDA.

Vermeir, S., Beullens, K., Meszaros, P., Polshin, E., Nicolai, B. M., \& Lammertyn, J. (2009). Sequential injection ATR-FTIR spectroscopy for taste analysis in tomato. Sensors and Actuators. B, Chemical, 137(2), 715-721. http://dx.doi.org/10.1016/j.snb.2009.01.056.

Vogel, J. T., Tieman, D. M., Sims, C. A., Odabasi, A. Z., Clark, D. G., \& Klee, H. J. (2010). Carotenoid content impacts flavor acceptability in tomato (Solanum lycopersicum). Journal of the Science of Food and Agriculture, 90(13), 2233-2240. http://dx.doi.org/10.1002/ jsfa.4076. PMid:20661902.

Wold, A.-B., Rosenfeld, H. J., Holte, K., Baugerod, H., Blomhoff, R., \& Haffner, K. (2004). Colour of post-harvest ripened and vine ripened tomatoes (Lycopersicon esculentum Mill.) as related to total antioxidant capacity and chemical composition. International Journal of Food Science \& Technology, 39(3), 295-302. http://dx.doi. org/10.1111/j.1365-2621.2004.00784.x. 